\title{
Welcome to the fourth year of Mucosal Immunology!
}

\author{
BL Kelsall $^{1}$, J Viney ${ }^{2}$ and P Garside ${ }^{2}$
}

$\mathrm{O}$ ver the past three years, owing to the efforts of a committed editorial board, a cadre of willing reviewers, and a highly effective managerial and publishing team, we are happy to report that we have made considerable progress in reaching our initial goal of making Mucosal Immunology the authoritative scientific journal for the field of mucosal immunology.

We have published primary research, reviews, and commentaries by authors from more than 20 countries that address most, if not all, mucosal tissues and cover a broad range of clinical and basic science topics. Furthermore, last June we received an objective measure of our progress, our first impact factor (IF) from the Institute for Scientific Information (ISI), now part of Thompson Reuters (see http:// thomsonreuters.com/products_services/ science/free/essays/impact_factor). The IF is commonly used to evaluate the "quality" of a journal, according to a relatively simple formula. The number of articles published in the prior two years is divided by the number of citations to those papers in the following (indexed) year. For new journals like Mucosal Immunology, the IF is determined after only two years of publication. Therefore, our first IF of 3.627, for 2009, reflects the average number of citations in 2009 to each article published in 2008 . We feel that this represents an excellent achievement for the journal. When compared to that of other new journals, an IF of 3.627 is exceptional. In addition, our first IF places us ahead of the majority of journals published in the field of immunology (35th of 128 journals) and on a par with many highly influential, well-established publications.

Further evidence of our progress was provided by a second quantitative tool used for comparing journals, the ISI's immediacy index (II). The II is the average number of times that an article published in a given year is cited over the course of the same year. The II for Mucosal Immunology for 2009 was 1.583 , placing us in the top $10 \%$ of immunology journals and indicating that our journal is now well recognized in the scientific community and is publishing highly relevant and timely articles. This bodes well for our IF in years to come.

Despite these indications of progress, it should be noted that the true value of these standard, convenient measures of "quality" is highly debated by the scientific community and journal editors. It is frequently argued that the IF is a reflection of "popularity" more than of the quality of the published material or the lasting impact of a journal on a field. In addition, the IF is highly disciplinespecific, and biased toward journals that encourage or practice self-citation.

As Editors, we want to assure the mucosal immunology community that 
we will continue to listen to your needs and value your opinions as we strive to publish high-quality, relevant, and timely articles from all subdisciplines within this burgeoning field, without an undue emphasis on popularity over content and with a measured regard for the importance of standard measures of "quality." The facts that we are receiving an increasing number of high-quality submissions each year and that world authorities remain willing to provide exceptional commissioned content make us hopeful that Mucosal Immunology is well on its way to becoming an established venue for the intellectual discourse that the field of mucosal immunology deserves.

๑ 2011 Society for Mucosal Immunology 